disabled author, did not take the opportunity to explore the experiences of nondisabled people (particularly women) when interacting with disabled people (especially women).

There is an urgent need for a discussion about disabled women's relationships with the women's movement and how the two interact. Towards the end of the book Lonsdale points out: 'In many ways, the objectives of the women's movement and groups of disabled women are the same: ending discrimination, developing a consciousness among women of how they are disadvantaged, and attempting to reshape and restructure society along feminist lines. But . . some of the symbols of combating oppression which the women's movement adopted, such as abortion on demand and a rejection of excessive femininity, have often been considered unacceptable to women with disabilities because they gloss over issues which are crucial to them.' (161)
Disabled women are an integral part of the women's movement, therefore the women's movement must reflect our needs, wishes and aspirations. It is unfortunate that Lonsdale did not explore the issues further by airing some of the debates more thoroughly.

Women and Disability is useful in terms of providing a comprehensive analysis of disability policies and the impact of these on disabled women. But in terms of providing a thorough analysis of the experiences of disabled women the reader is short-changed. In a field where there is very little written material available, one must be wary of treating it as an authoritative text. Our voices as disabled women are only heard through the mouthpiece of a nondisabled woman. This must make the reader question whether the written text really does justice to our experiences as disabled women.

Nasa Begum

\section{Issues of Blood: The Politics of Menstruation}

\section{Sophie Laws}

Macmillan: London, 1990

ISBN $0333482344 £ 9.99 \mathrm{Pbk}$;

ISBN $0333482336 £ 35.00 \mathrm{Hbk}$

Most of the feminist work concerned with menstruation has come from the matriarchalist/essentialist radical-feminist schools of thought (Weideger, 1978; Delaney, Lupton and Toth, 1976; Shuttle and Redgrove, 1978). Sophie Laws's painstaking investigation into the politics of menstruation is a self-conscious exercise in developing a socialconstructionist and yet radicalfeminist perspective which refutes biological determinist and universalist explanations. She seeks instead to describe and make sense of social meanings and explore the ways in which competing social defi- nitions interact. Looking at the social treatment of menstruation and how the practices of our own culture spell out messages about male superiority and compulsory heterosexuality to women, Laws argues that in a patriarchal society, menstruation is seen by men as a marker of femaleness and used to convey a particular belief in women's inferior status.

In order to present a social constructionist argument, Laws's first task was to challenge the universal menstrual taboo theory of much anthropological research in this area. The taboo theory proposes that menstrual blood is inherently dirty and that men are naturally repulsed by a physical function they do not share with women. Laws goes to great lengths to reveal the existence of an immense variety of cultural practices relating to menstruation and argues that it is not useful to reduce 
the complexity and variety of ritual, practice and beliefs around menstruation across different cultures to generalized statements about taboos. The tendency of Western male anthropologists to emphasize menstrual taboo says more about their own preoccupations than it reveals about the cultures they have observed.

Rather than the universalist notion of taboos, Laws has identified a menstrual 'etiquette' which operates in contemporary British secular culture. Defined by Laws as 'a set of social practices which express and reinforce the distinctions between people of different social statuses' I found this notion of etiquette useful, although it does not allow for an examination of the role played by religious discourse in constructing widely held beliefs about menstruation. The etiquette requires that women may not make men aware of the existence of menstruation either implicitly or explicitly; those who do are ridiculed, harassed or avoided by men. Many of us will recognize the descriptions cited by Laws of the extraordinary lengths women have gone to in order to conceal the fact that they are bleeding.

Starting with the hypothesis that what men say about menstruation has engendered women's sense of shame, Laws selected to research into what a group of men had to say on the subject, probing especially questions of how they thought they had aquired the attitudes and beliefs they held. This is the type of research very few feminists would choose to undertake as many of us have an idea of the hateful nature of many men's reactions to menstruation. Laws herself found it hard to conceal her distaste for much of what she heard from her subjects. This raised methodological problems for Laws as her lack of empathy with her subjects made deciphering the interviews difficult and she failed to provide a coherent description of their views. Sociologists have tradition- ally relied greatly on empathy with their research subjects in making their interpretations and Laws is aware that her work lacks this insight. The personal strain of carrying out this research is highlighted repeatedly throughout the text, leaving me wondering whether there wasn't a less traumatic way of obtaining the data.

Laws's distaste for her subjects permeates the text and creates a mood of deep pessimism throughout the book, something much radicalfeminist writing manages to do. It would be a shame if this put people off as the book positively bursts with data and insight. I did feel, however, that Laws's discussion of gynaecological discourse on menstruation was far too brief and not related to wider social attitudes. That both gynaecologists and Laws's men believe women imagine or exaggerate menstrual pain was an important discovery, however the relationship between the two discourses was not adequately explored. Laws suggests that as most gynaecologists are men then this is simply an echo of male beliefs about menstruation. Laws sees no need to discuss difference between men, which allows her to see all men as having the same access to power and influence, a position which prevents her from examining the particular power of certain discourses.

The public denial of menstrual pain stands in an interesting contrast to 'premenstrual tension'. That men more readily accept the impact of hormonal fluctuations on women's mood changes rather than believe that we often experience real, sometimes excruciating pain, is evidence of a system of gender stereotyping which clings to the notion that women are essentially irrational, victims of our hormones. The construction of PMT into a diseaselike category has created very negative connotations for women. Thus, in cases of female violence the judiciary will now accept a plea of temporary 
insanity by virtue of hormonal fluctuations, yet doggedly resist women's pleas of provocation even in the most horrific cases of domestic violence. The brutality experienced by some women at the hands of men they live with still goes unacknowledged within legal discourse while PMT is eagerly embraced as confirmation of women's biologically determined emotional instability. Laws argues convincingly that in this case the dismantling of menstrual etiquette has not necessarily been liberatory.

Menstruation may not be important in itself, but it is highly symbolic of femaleness and the ways in which men deal with it reveal aspects of how they view women in general. The main problem with Laws's analysis is her monolithic view of male power, unmediated by considerations of class, race or age. When I first read this book, I was left with the same sense of hopelessness and exasperation which permeates the text. However, on a closer reading and Laws's pessimism notwithstanding, I discovered that it does contain some cause for optimism which is not acknowledged by the author.

It was evident from what some of the men had told Laws that some women do indeed act within their relationships to challenge men's preconceived and misogynist ideas about women's bodies; some women are refusing to hide the fact of their menstruation from men they know or live with; some women are actively seeking sex with men while menstruating because they experience heightened desire at this time; and some men (albeit only a few from this small sample but surely that is positive) are concerned to understand more about menstruation and how women feel about it. It is the public arena which remains dominated by powerful institutions (law, medicine) and largely male-only groupings which remains overtly hostile to women defining their own bodily and social experience. It does not help our understanding of power in society, who has it and who benefits from it, to see all men as members of an oppressive brotherhood which seeks ultimately to keep us in our rightful place. Such a position presents women only as passive recipients of male oppression and is negative about the possibility of change. It is crucial, therefore, to remind women not only of how far we have to go, as Laws does, but also to celebrate how far we have come.

\section{Shiona McArthur}

\section{References}

DELANEY, J., LUPTON, M. J. and TOTH, E. (1976) The Curse: A Cultural History of Menstruation New York: E. P. Dalton. ShutTle, Penelope and REDGROVE, Peter (1978) The Wise Wound: Menstruation and Everywoman London: Victor Gollancz; Harmondsworth: Penguin, 1980. WIEDEGER, Paula (1978) Female Cycles London: Women's Press. 